\title{
A vivência dos familiares de crianças e adolescentes portadores de diabetes mellitus tipo 1
}

\author{
The experience of family members of children and adolescents with type 1 diabetes mellitus
}

La experiencia de los familiares de niños y adolescentes con diabetes mellitus tipo 1

Dalila Teixeira Leal ${ }^{1}$, Flávia Andrade Fialho², lêda Maria Ávila Vargas Dias ${ }^{3}$, Lilian do Nascimento ${ }^{4}$, Wivian Cristiane Arruda ${ }^{5}$

\section{RESUMO}

O estudo teve como objetivo descrever os aspectos significativos da vivência familiar de crianças e/ou adolescentes diabéticos. A partir de uma abordagem qualitativa, o estudo foi realizado no Pólo da Criança e Adolescente Insulino Dependente, do Serviço de Controle de Hipertensão, Diabetes e Obesidade, da Secretaria Municipal de Saúde de Juiz de Fora/MG. Os sujeitos foram os familiares dos usuários desse serviço. Os dados foram coletados por meio de uma entrevista aberta e passaram por uma análise de conteúdo, modalidade temática, que permitiu a construção das seguintes categorias: A descoberta da doença; As dificuldades encontradas com o surgimento da doença e as mudanças decorrentes dessa vivência; O convívio social da criança e do adolescente diabético. Na conclusão, destacamos o quanto o diabetes mellitus tipo 1, afetam toda uma estrutura familiar e a importância do enfermeiro compreender essa situação vivenciada pelos familiares de crianças/adolescentes diabéticos e, desse modo inseri-los num plano de cuidados resolutivo.

Descritores: Diabetes Mellitus; Família; Criança; Adolescente; Enfermagem.

\section{ABSTRACT}

The objective of this study was to describe the significant experiences of family members living with children and/or adolescents with type 1 diabetes. Using a qualitative approach, the study was developed at the Center for Insulin-Dependent Children and Adolescents, at the Juiz de Fora (Minas Gerais) Health Department Hypertension, Diabetes and Obesity Control Service. The subjects were the family members of the clients using the referred service. The data were collected through open interviews and subjected to thematic content analysis, which permitted the following categories to be constructed: the discovery of the disease; the difficulties faced with the onset of the disease and the changes resulting from this experience; and the social lives of diabetic children and adolescents. In conclusion, we highlight how greatly type 1 diabetes mellitus affects the entire family structure, and how important it is for nurses to understand the situations experienced by the family members of diabetic children/adolescents and including them in an effective care plan.

Descriptors: Diabetes Mellitus; Family; Child; Adolescent; Nursing.

\section{RESUMEN}

El estudio objetivó describir los aspectos significativos de la experiencia familiar de niños y/o adolescentes diabéticos. Abordaje cualitativo, estudio realizado en el Polo del Niño y Adolescente Insulinodependiente del Servicio de Control de Hipertensión, Diabetes y Obesidad de la Secretaría Municipal de Salud de Juiz de Fora/MG. Los sujetos eran familiares de pacientes del servicio. Datos recolectados mediante entrevista abierta, se efectuó luego análisis de contenido, modalidad temática que permitió construir las categorías: El descubrimiento de la enfermedad; Dificultades encontradas ante la aparición de la enfermedad y los cambios derivados de la experiencia; Convivencia social del niño y del adolescente diabético. En la conclusión destacamos cuánto la diabetes mellitus tipo I afecta a toda la estructura familiar y la importancia de que el enfermero comprenda esa situación experimentada por los familiares de niños/adolescentes diabéticos e insertarlos en un plano de cuidados resolutivos.

Descriptores: Diabetes Mellitus; Familia; Niño; Adolescente; Enfermería.

\footnotetext{
${ }^{1}$ Enfermeira. Juiz de Fora, MG, Brasil. E-mail: lealdalila@hotmail.com.

2 Enfermeira, Discente do Programa de Pós-Graduação em Enfermagem - nível Mestrado, Faculdade de Enfermagem, Universidade Federal de Juiz de Fora (UFJF). Juiz de Fora, MG, Brasil. E-mail: flavinhafialho@bol.com.br.

3 Enfermeira, Doutora em Enfermagem, Professora Adjunta, Faculdade de Enfermagem, UFJF. Juiz de Fora, MG, Brasil. E-mail: vargasdias@hotmail.com.

${ }^{4}$ Enfermeira. Juiz de Fora, MG, Brasil. E-mail: lilica.vip.jf@bol.com.br.

${ }^{5}$ Enfermeira. Juiz de Fora, MG, Brasil. E-mail: wivianarruda@bol.com.br.
} 


\section{INTRODUÇÃO}

Considerando o potencial de morbidade e o grande número de pessoas acometidas, pode-se dizer que o diabetes mellitus tipo 1 atualmente reveste-se de grande importância social. Esta patologia é resultante de processos patogênicos específicos e está associada a complicações, disfunções e insuficiência de vários órgãos, especialmente olhos, rins, nervos, cérebro, coração e vasos sanguíneos, constituindo-se numa doença complicada e dolorosa, que interfere no estilo de vida ${ }^{(1)}$.

As doenças crônicas, consideradas incuráveis e permanentes, exigem que o indivíduo re-signifique sua existência, adaptando-se às limitações, frustrações e perdas. Essas mudanças são intensificadas quando nos referimos a uma criança e/ou adolescente, pois o esperado é que vivam situações de saúde para crescer e se desenvolver dentro dos limites da normalidade.

Ao se defrontar com uma doença crônica, como o diabetes mellitus, a criança e/ou adolescente têm seu comportamento modificado. Essa experiência desconhecida pode the trazer sentimentos de culpa, medo, angústia, depressão e apatia, ameaçando a rotina do seu dia-a-dia e de sua família(2).

Quando os familiares descobrem tal doença em seus filhos, defrontam com dúvidas, incertezas, revoltas e desespero. Não obstante, buscam explicações para entenderem melhor essa complicação e soluções que minimizem os possíveis efeitos ${ }^{(3)}$. Os familiares inicialmente são expostos a uma situação assustadora e desconhecida e vão aos poucos tomando conhecimento da extrema gravidade da doença( ${ }^{(4)}$.

Neste momento é oportuno a intervenção da equipe de saúde, pois esta situação demanda um envolvimento harmonioso e contínuo de pacientes, familiares e profissionais de saúde que, na busca de atingir o equilíbrio biológico, psíquico e social, implementam várias intervenções.

O diabetes mellitus (DM), como toda doença crônica exige adaptação em vários âmbitos, o que torna evidente a necessidade da interação da família em todo esse processo ${ }^{(5)}$, principalmente, considerando o quanto é salutar o apoio social e familiar.

A proposiçao do presente estudo se justificativa pela relevância dessa problemática e pelo desafio que se coloca para os profissionais de saúde para ampliarem o foco de atenção para além do portador da doença, pois assim, se ampliará também a abrangência da resolutividade. Isso se aplica, principalmente, a crianças e/ou adolescentes diabéticos que, geralmente, tomam como base para seus hábitos e costumes o grupo familiar e/ou social.

Compreender esses aspectos e a dimensão da subjetividade que envolve as relações familiares no contexto das doenças crônicas é uma questão importante e que merece investigações que permitam sua compreensão. Рага o delineamento do presente estudo tomou-se como base a questão norteadora: como se configura a vivência dos familiares de uma criança e/ou adolescente portador de diabetes mellitus tipo 1 ? Para responder a essa pergunta, foi traçado o objetivo de descrever os aspectos significativos da vivência familiar de crianças e/ou adolescentes diabéticos.

\section{METODOLOGIA}

Рага atender aos objetivos do presente estudo, elegeu-se a pesquisa qualitativa como abordagem metodológica a ser seguida. Este tipo de estudo enfatiza a importância de conhecer, entender e interpretar a natureza das situações e eventos quer sejam eles passados ou presentes, respondendo a questões muito particulares, preocupando-se com um nível de realidade que não pode ser quantificado(6).

Referente ao procedimento da pesquisa, pode-se dizer que, após a aprovação pelo Comitê de Ética em Pesquisa da UFJF, parecer $n^{\circ} 274 / 2007$, iniciou-se a fase de coleta de dados, tendo como campo de estudo o Polo da Criança e Adolescente Insulino Dependente do Serviço de Controle de Hipertensão, Diabetes e Obesidade (SCHDO) da Secretaria Municipal de Saúde de Juiz de Fora. Vale esclarecer que o presente estudo é um recorte de um estudo maior realizado no âmbito da iniciação científica.

Os sujeitos do estudo foram os familiares dos usuários deste serviço, considerando-se como critério de inclusão, ser o responsável pelo usuário e ser voluntário da pesquisa. Todos os familiares que compareceram ao serviço no período de coleta dos dados foram convidados a participar do estudo. Participaram aqueles que, após conhecer o objetivo do estudo e assinarem o Termo de Consentimento Livre e Esclarecido, foram entrevistados.

As entrevistas foram conduzidas a partir da seguinte questão norteadora: “Conte para mim a sua vivência 
referente à repercussão do diabetes mellitus no cotidiano familiar". Com aquiescência dos participantes, as entrevistas foram gravadas e transcritas em sua totalidade logo após sua realização para que nenhum detalhe importante fosse perdido.

No total foram realizadas 20 entrevistas, sendo este número definido pela saturação dos dados. A saturação ocorre quando as informações que estão sendo compartilhadas com 0 pesquisador se tornam repetitivas, e a inclusão de outros participantes não resulta em idéias novas ${ }^{(7)}$.

Ao término da coleta de dados, partiu-se para a fase de análise, em que foi empregada a análise de conteúdo, modalidade temática que consiste em descobrir os núcleos de sentido que compõem uma comunicação, cuja frequência signifique alguma coisa para o objetivo analítico visado. Frequentemente, esta técnica de análise se encaminha para a contagem de frequência das unidades de significação como definidoras do caráter do discurso; ou ao contrário, qualitativamente, a presença de determinados temas denota os valores de referência e os modelos de comportamento presentes no discurso(8).

Este tipo de análise desdobra-se em três etapas: préanálise, que consiste na seleção dos documentos e determina a unidade de registro; exploração do material, codificação que permite a transformação dos dados brutos, visando alcançar o núcleo de compreensão do texto; tratamento dos resultados obtidos e interpretação, que permitem colocar em relevo as informações obtidas ${ }^{(8)}$.

Considerando que a análise de conteúdo permite a análise dos aspectos subjetivos presentes nos dados, esta foi realizada a partir da leitura exaustiva das entrevistas, que permitiu o desdobramento em categorias analíticas emergidas dos dados coletados. Os depoimentos dos sujeitos foram identificados no texto por numeração arábica de acordo com a ordem da realização da entrevista.

\section{APRESENTAÇÃO E DISCUSSÃO DOS RESULTADOS}

Os resultados da pesquisa, de modo geral apontam para a ideia de que a doença crônica, principalmente o diabetes mellitus tipo 1, carrega consigo valores emocionais, psicológicos, econômicos e sociais que afetam o dia-a-dia de toda uma estrutura familiar. Esses valores tornam-se ainda mais evidentes quando nos referimos a criança e ao adolescente diabético, uma vez que o esperado é que a criança viva a normalidade; portanto, ao corolário desta expectativa está uma situação inusitada, descrita a seguir por quem a vivencia. Os dados indicaram a construção de sua síntese por meio de duas categorias analíticas, a saber: a descoberta da doença; as dificuldades encontradas com o surgimento da doença e as mudanças decorrentes dessa vivência.

\section{A descoberta da doença}

Nessa categoria foi explorada a descoberta do diabetes mellitus tipo 1 como um episódio inesperado, tanto para o sujeito acometido pela patologia, quanto para seus familiares. Representa uma interrupção, um abalo nos valores cultivados antes da doença, tornando o futuro duvidoso. Além disso, sabe-se que o tratamento é duradouro, a evolução é lenta e a rotina diária acaba sofrendo implicações, como a restrição de alguns alimentos e a exigência de hábitos mais saudáveis.

A doença passa a fazer parte da vida de seu portador como algo incerto, que pode ocasionar: preocupação, dificuldade de aceitação, mudança de rotinas/hábitos, medo do desconhecido, da morte e de consequências trazidas pela doença(2). O mesmo para os familiares, principalmente os pais, que acabam carregando para si sentimentos de indignação, medo e, o principal deles, a culpa. Conforme ilustram as falas:

[...] ela começou aparecer diabetes quando eu comecei a trabalhar fora, ai trabalhava de dia e de noite [...] e ela ficava sozinha, né! Então desencadeou, acho que foi por isso, né? Acho que ela sentiu muito a minha falta $e$ desencadeou a diabetes dela (mãe se emociona e chora). (E6)

[...] A diabetes pra mim foi uma tragédia[...] eu tinha minha mãe que era diabética, tinha perdido ela há pouco tempo. Aí aquilo virou uma bananosa na minha cabeça. Até entender por quê ele estava diabético, que não era igual ao dela, e até achar alguém pra me ajudar, ter apoio, que é muito difícil no princípio [...]. (E1)

Torna-se evidente no depoimento dos familiares o sentimento de culpa pelo surgimento da doença, além do significado negativo dessa experiência. Os primeiros sintomas da doença surgem como uma dificuldade para os familiares, que na maioria das vezes não são preparados para lidar com a enfermidade. Quando a 
doença surge com a necessidade de internação, o sentimento de medo e insegurança torna-se ainda maior. O desconhecimento com relação à doença também contribui para essas dificuldades:

\section{[...] foi sério a diabetes em nossa vida, porque eu era muito} nova, não entendia o que era o diabetes em si. Ela passava muito mal, tinha muita queda de glicose, ficávamos 15 dias em casa e 15 dias no hospital. Pra mim foi a pior experiência da minha vida porque era minha primeira filha, depositei todas as minhas expectativas e de repente descubro o diabetes, uma doença que para mim só dava em pessoas idosas [...] (E 12)

Desde o início dos sintomas até a definição dos diagnósticos e tratamento, a família vivencia uma fase de crise, caracterizada por um período de desestruturação e incertezas, tendo que aprender a lidar com sintomas, procedimentos diagnósticos e terapêuticos, para assim reorganizarem suas vidas ${ }^{(2)}$. Percebe-se também que muitas vezes a descoberta do diabetes ocorre tardiamente, o que ocasiona várias complicações na saúde do diabético. O familiar associa os sintomas a várias outras causas, ou mesmo banalizam os indícios, só recorrendo a um diagnóstico especializado quando os sintomas já estão bem evidentes.

\section{[...] Eu descobri a diabetes dela porque ela bebia água o dia} inteirinho, só que não tava comendo nem nada, durante três dias, só água.[...] (E5)

\section{[...] Ele não sabia explicar o que ele tava sentindo. Ele dizia} que tava com dor de barriga. Aí ele ficou três dias em casa assim, sem alimentar sem nada. Pra mim ele tava com dor de barriga.[...] (E 7)

O diagnóstico na criança é, em geral, suspeitado diante das manifestações clínicas. A hiperglicemia na maioria das vezes é bastante acentuada, e provoca glicosúria e diurese osmótica, com consequente desidratação. A necessidade de compensar a desidratação leva à modificação dos hábitos trazendo a enurese noturna, poliúria e polidpsia. O intenso catabolismo e a perda eletrolítica levam ao emagrecimento, fraqueza e desânimo ${ }^{(9)}$.

Ao receber o diagnóstico da doença, de uma forma geral, um grande impacto emocional foi sofrido pelos familiares. Algumas preocupações passaram a fervilhar no âmbito familiar, sendo uma delas o temor com relação à indiferença e ao preconceito que seus filhos pudessem vir a sofrer.

[...] Foi terrível! Terrível! A diabetes foi pra mim o pior desafio que eu encontrei na vida. Até hoje pra mim, me faz (pausa na fala), a doença dela faz mais mal a mim, eu não aceito! [...]. (E18)

[...] até acostumar, que ele mudou o jeito, às vezes ele tava brincando e passava mal, as crianças começavam a falar dele... Aquele movimento todo... Hoje em dia é mais fácil pra ele e pra mim também [...](E15)

Toda a limitação causada pela doença, as sequelas geradas e as modificações na vida da criança e/ou do adolescente diabético podem resultar em uma situação de estresse para a família. As perdas sociais, biológicas e psíquicas podem dar início a um processo de luto. Desta forma, junto com a descoberta da doença surgem conflitos que influenciam a vida do doente e de seus familiares. Isso determina uma fase muitas vezes turbulenta, principalmente para os familiares que tendem a se questionar o porquê do surgimento da doença em suas vidas.

Indubitavelmente o diabetes mellitus tipo 1 acarreta implicações individuais que se referem à aceitação da doença e do tratamento. Implica em custos econômicos e custos sociais, interferindo na qualidade de vida e sobrevida dos indivíduos(10).

Apesar de não esconderem suas incertezas e angústias diante do futuro de suas crianças e adolescentes portadores do diabetes, alguns familiares mostram-se conformados após a descoberta da doença, acabando por aceitar a situação de saúde dos filhos, conforme os relatos a seguir:

[...]Não gosto que ele é assim! Nunca vou gostar! Mas me acostumei com a diabetes dele! [...] É, agora a gente procura aceita melhor a diabetes (pausa na fala) (mãe chora). Eu não tenho outra escolha, né? (pausa na fala) (mãe chora) [...] Me desesperei e tal. Hoje, fazer o quê? Tem que aceitar, né? Hoje a gente vê com outros olhos, né?

A doença crônica é aceita a partir de um significado que the é atribuído e que nomeia tal experiência. Todos os membros vivenciam o processo de adoecer com os recursos que the são disponíveis, portanto, diferentes 
significados surgem de acordo com a história pessoal de cada membro(2).

A aceitação é um passo importante para a terapêutica; entretanto, está relacionada à singularidade de cada indivíduo, o que significa dizer que alguns aceitarão mais facilmente e outros podem até nunca chegar a essa condição. Além disso, a aceitação demanda tempo e suporte, seja familiar ou profissional. Neste sentido, é imprescindível a importância do paciente e familiar receber do profissional informações sobre o seu estado de maneira clara e no momento adequado.

A compreensão empática da equipe multiprofissional que atenda a família facilitará a adesão do adolescente diabético ao tratamento e sua integração na sociedade em que vive. Portanto, devido aos problemas e complicações que o diabetes traz para a vida da criança e/ou adolescente e sua família, cabe aos profissionais de saúde estarem atentos na identificação das pessoas com risco para o diabetes mellitus tipo 1, intensificando as ações de promoção e controle da doença.

\section{As dificuldades encontradas com o surgimento da doença e as mudanças decorrentes dessa vivência}

Nesta categoria são exploradas as dificuldades físicas, emocionais e psicológicas que o surgimento do diabetes em crianças e adolescentes trazem e as repercussões desse processo, que gera medo e insegurança para a família. Além dessas, dificuldades sociais e financeiras também passam a fazer parte do cotidiano familiar. A análise das entrevistas mostrou o quanto essa doença permeia a vivência familiar de conflitos, em que até mesmo situações de constrangimento são vivenciadas pelos pais da criança e ou adolescente portador de diabetes.

[...] eles passam muito mal, o meu pelo menos passou muito mal e passa até hoje. É difícil a gente entender, ao mesmo que tá alta aquilo, tá baixo, aí dá hipoglicemia, passa mal no meio da rua, tem pessoas que não conhecem ainda e acha que tá tendo outra coisa. Não é fácil, a gente fica até com vergonha [...] (E4)

[...] Porque logo que começou a diabetes dele era mais complicado, tinha o aparelho, mas era muito caro, a gente não tinha condições de ter, não podia comprar. Agora o governo manda pra gente, agora ele tem, então é tudo mais fácil, mas mesmo assim é muito difícil ter [...] (E10)
Os depoimentos mostram que as dificuldades vivenciadas pelo familiar da criança e/ou adolescente portador de diabetes abrangem várias dimensões. Essa situação mobiliza a familia para transpor vários obstáculos e lançar mão de mudanças em seu cotidiano. Em alguns casos, um dos pais refere que precisa estar disponível para cuidados em tempo integral, tendo que abrir mão de desenvolver suas atividades ou parar de trabalhar fora, havendo com isso redução da renda familiar.

[...] рra mim, mudou minha vida toda com a diabetes do meu filho. Eu sempre trabalhei fora, sou doméstica, sempre deixava ele pra ir trabalhar. Ele podia ficar em casa sozinho, hoje não posso deixar mais. E me dá muito trabalho, né? [...] (E11)

[...] a vida da gente muda muito com a diabetes, muda sim! Muda $100 \%$. Vira a vida de cabeça pra baixo, porque não tem jeito [...] (E19)

Outro fator que contempla mudanças ocasionadas no cotidiano familiar, bem como da própria criança e adolescente diabético, é o tratamento da doença, que requer cuidado e atenção, muitas vezes tornando-se um gerador de conflito entre familiares e portadores da doença.

[...] você não pode pegar um remédio e despejar pela boca abaixo de uma criança, né? É complicado. Antes tava sendo mais fácil, agora to achando mais difícil, o ano vai passando, as idades, coisa assim, to achando mais difícil controlar a diabetes dela. (E4)

A existência de sintomas dolorosos associados à doença e às constantes avaliações e tratamentos podem alterar o funcionamento físico e mental da criança, bem como sua interação com o meio ambiente. As repetidas visitas ao médico e a necessidade de assegurar que as medicações sejam dadas em horas específicas são fatores que potencializam o estresse de mães e pais com um filho com doença crônica. Eles sentem seus papéis parentais muito mais exigidos do que situações em que a criança é saudável(2).

A mudança na rotina da família é inevitável e radical. Dentre as adequações que a família tem que realizar, a alimentar é a mais evidente. Alguns alimentos são proibidos ou restritos, outros são adaptados, e há 
também os que são inseridos ao hábito alimentar, sendo que há necessidade de maior rigor nos horários das refeições. A reestruturação alimentar é uma das coisas mais difíceis de inserir na nova rotina ${ }^{(11)}$.

Essa questão é considerada por grande parte dos familiares como uma barreira, uma vez que exige controle de hábitos alimentares, com restrição de alguns alimentos, principalmente os doces, gerando um conflito entre familiares e o portador da doença.

[...] o mais difícil do diabetes é o doce, né? Que tem que esconder muito os doce, o açúcar, tudo que é doce ela quer comer, porque tem 13 anos ainda. Aí quer comer. Aí eu considero a parte mais difícil. [...] (E9)

[...] Hoje em dia, por exemplo, nós estamos na época de Páscoa, é difícil você comprar pra ele um ovo de páscoa diet grande, você acha dos pequenos, enquanto todo mundo quer um ovo bem grande, bem enorme e você compra um pequeno, então isso é complicado. (E13)

Na fala dos sujeitos transparece as dificuldades no controle da dieta, evidenciando o quanto algumas datas comemorativas tornam-se conflitantes, tanto para o diabético como para seus familiares. Essa dificuldade de controle da dieta se estende ao ambiente escolar, alterando o convívio social.

[...] Nessa Escola que ele está hoje tá sendo mais fácil porque ele tem um colega que também tem diabetes, então ele não tá se sentindo muito diferente dos outros. Na escola que ele tava ano passado ele se sentia totalmente diferente, excluido, porque os colegas começavam a ter aquela separação, foi um dos motivos que eu tirei ele da escola também. Aí chegando nessa escola, tem um colega, e ainda o diretor da escola também é diabético. Então fica mais fácil para ele não se sentir tão fora, tão excluído, né? Os colegas fazem muitas festas aí eles já levam pro pessoal diabético separado, é o bolo, o refrigerante, é tudo diferente[...] (E8)

O depoimento selecionado mostra o quanto as adaptações, necessárias em decorrência da patologia repercutem no âmbito escolar, que evidencia a necessidade de adaptação da alimentação, da prática de exercícios e mesmo de atividades rotineiras impostas pela doença para a criança e o adolescente diabético. Para estes últimos, outros problemas são acrescidos em decorrência da ampliação do convívio social, das atividades diárias e das experiências com o trabalho, como mostram os depoimentos:

[...] às vezes corre uma balinha do colega, né? (risos), mas assim, ele assim, é um menino 100\%. Mas, ele queixa em relação aos amigos, o pessoal não compreende. (E1)

[...]Ele começou a trabalhar esses dias, ficamos tão felizes, primeiro emprego certinho, com horário certo, salário bom em um lugar legal. Só que deu tudo errado, ele desmaiou no serviço, foi muito chato, deu aquela impressão que ele tava doente. (E20)

[...]Ele falou comigo ontem, "tia com dois dias de serviço como que eu vou pedir dispensa ao meu patrão para ir ao médico? Ele vai achar que eu to doente e vai me mandar embora". (E3)

A escola torna-se local principal de convivência social da criança e/ou adolescente. Na escola estes acabam tendo que lidar com a doença frente à sociedade (colegas, professores e demais). É neste espaço também que se percebe fortemente a intervenção de aspectos como a dieta imposta pela doença. Assim, podem ocorrer mudanças de comportamento nesse ambiente de convívio, tendo em vista as alterações ocorridas em suas vidas.

Um fato preocupante emergido nas falas dos familiares foi o relato de que algumas crianças e/ou adolescentes, para burlar as limitações alimentares impostas pelo diabetes, fazem uso em excesso da insulina. Ao administrar mais insulina, a glicose diminui e, consequentemente, elas podem consumir os alimentos que desejam, mas que não deveriam.

[...] Ela prefere comer! Ela prefere tomar insulina e poder comer. Então ela come em excesso e quando a insulina faz efeito faz em excesso também, porque ela exagera, aí prejudica ela. (E2)[...] O negócio dela é comer! Ela sempre comeu de tudo que queria, nunca se alimentou adequadamente, então às vezes ela aumenta a insulina para poder comer mais. (E6)

A doença acarreta mudanças significativas na relação do diabético com seu próprio corpo e com o mundo ao seu redor, principalmente, porque é pelas restrições alimentares que o diabético toma consciência de suas limitações. Por essa razão, o conflito entre o desejo 
alimentar e a necessidade de contê-lo está sempre presente ${ }^{(12)}$.

Desta forma, muitos familiares desenvolvem maneiras para contornar essas situações de forma a afetar o mínimo possível o bem-estar das crianças e adolescentes. Algo significativo foi o relato da mudança, por parte de toda a família, de alguns hábitos alimentares. [...] Houve uma mudança de hábito de alimentar da família inteira, cortamos açúcar, não entra açúcar lá em casa, só adoçante, passei a tomar adoçante tanto eu como meu marido. Eu cheguei a perder peso [...] (E16)

Os diabéticos têm a mesma necessidade nutricional e calórica de qualquer pessoa e não precisam comer apenas determinados alimentos. A reestruturação alimentar é um dos pontos críticos na rotina familiar, pois para o êxito deste processo envolve mudanças apropriadas e mecanismos de adaptação(5).

A pratica de atividade física também foi relatada como algo que passou a permear a vida de alguns familiares após a descoberta da doença na criança e/ou adolescente [...] a princípio foi muito difícil, ele não aceitava alimentação, não aceitava o exercício. Agora ele mesmo já fala: mãe vamos caminhar, mãe vamos andar de bicicleta, vamos jogar peteca, essas coisas assim, que a gente fica fazendo no final de semana e que antes a gente não fazia. (E14)[...] a atividade física virou rotina para os três, apesar do pai ser mestre em capoeira, mas nós dois não tínhamos muito o hábito de fazer atividade física. $E$ a partir daí, da diabetes, nós fazemos a atividade física e a alimentação melhorou muito[...](E17)

Os benefícios da prática de atividade física regular para a saúde têm sido amplamente documentados. A melhora das condições fisiológicas advindas dessa prática é ainda mais importante nos portadores de diabetes mellitus, uma vez que o risco de mortalidade por doenças coronarianas é de duas a quatro vezes maior nesses indivíduos ${ }^{(13)}$.

A participação familiar é fundamental para o êxito da aquisição de hábitos mais saudáveis por parte da criança e do adolescente diabético, que, ao compartilharem do apoio da família, sentiram-se motivados a persistir.

\section{CONSIDERAÇÕES FINAIS}

O estudo permitiu conhecer a dimensão que o diabetes assume na vida de familiares de crianças e/ou adolescentes acometidos pela doença, sendo inúmeros os desafios a serem transpostos nesta vivência.

Indubitavelmente é de suma importância a família no dia-a-dia de uma criança e/ou adolescente diabético, pois a forma como esta convive, sua atitude e postura e principalmente a representação que o diabetes assume em sua vida, desde a descoberta da doença até os mecanismos desenvolvidos para conviver com ela, influenciam sobremaneira no comportamento do portador.

Quando o profissional de saúde, principalmente o enfermeiro, reconhece a importância dos familiares, tornam-se amplas as possibilidades de cuidado. Nesse contexto, percebe-se que, embora tenha ocorrido uma transição da visão biologicista (de cuidar apenas da doença) para a concepção holística (do cuidado integral de um individuo), o cuidado ainda não concentra essa integralidade que pensamos e acreditamos estar fazendo, uma vez que esse cuidado incorpora valores, hábitos, costumes, vivências das pessoas acometidas pela enfermidade, e, mais ainda, por aqueles que estão mais próximos a ela, no caso os familiares. Tal idéia nos pareceu notória após a realização deste estudo.

Desta forma, acreditamos que o enfermeiro, agindo na promoção da saúde, poderá desenvolver um plano de cuidados bem mais resolutivo com estas crianças e adolescentes caso consiga o apoio dos familiares e/ou pessoas próximas ao diabético. Entretanto, para que isso ocorra, é necessário que o profissional esteja atento para oferecer-lhes apoio, orientando, acolhendo, prestando auxílio em suas dificuldades, angústias, medos e dúvidas decorrentes do diabetes. A troca de experiências é uma alternativa bem rica nessa prática, mesmo porque, conforme já foi mencionado, o diabetes não ocasiona mudanças somente na vida do seu portador, ele influencia as pessoas ao seu redor, alterando hábitos, costumes, pensamentos e perspectivas de vida.

É relevante ainda destacar que não buscamos responsabilizar unicamente a família no controle e tratamento do diabetes, mas propomos uma troca, um complemento desta com os profissionais de saúde, buscando inserir o diabético, sua família, e os profissionais de saúde como co-responsáveis na realização do cuidado integral ao portador da doença. 


\section{REFERÊNCIAS}

1. Ministério da Saúde. Diabetes Mellitus. Cadernos de Atenção Básica - n. ${ }^{\circ} 16$ [Internet]. Brasília (Brasil): Ministério da Saúde; 2006 [cited 2012 mar 30]. 64 p. Available from: http://189.28.128.100/dab/docs/publicacoes/cadernos_ab/abcad16. $\mathrm{pdf}$.

2. Pilger C, Abreu IS. Diabetes mellitus na infância: repercussões no cotidiano da criança e de sua família. Cogitare Enferm [Internet]. 2007 [cited 2012 mar 30];12(4):494-501. Available from: http://ojs.c3sl.ufpr.br/ojs2/index.php/cogitare/article/view/10076/6 $\underline{928}$.

3. Sales CA, Tironi NM, D'Artibale EF, Silva MAP, Violin MR, Castilho BC. O cuidar de uma criança com diabetes mellitus tipo 1: concepções dos cuidadores informais. Rev. Eletr. Enf. [Internet]. 2009 [cited 2012 mar 30];11(3):563-72. Available from: http://www.fen.ufg.br/revista/v11/n3/v11n3a13.htm.

4. Brito TB, Sadala MLA. Diabetes mellitus juvenil: a experiência de familiares de adolescentes e pré-adolescentes. Cien Saude Colet [Internet]. 2009 [cited 2012 mar 30];14(3):947-60. Available from: http://www.scielo.br/pdf/csc/v14n3/31.pdf.

5. Alencar DC, Alencar AMPG. O papel da família na adaptação do adolescente diabético. Rev. Rene [Internet]. 2009 [cited 2012 mar 30];10(1):19-28. Available from: http://www.revistarene.ufc.br/vol10n1 html site/a02v10n1.htm.

6. Silva JM, Silveira ES. Apresentação de trabalhos acadêmicos: normas e técnicas. 4th ed. Juiz de Fora: Tempo; 2006.

7. Minayo MCS. Pesquisa social: teoria, método e criatividade. 26th ed. Petrópolis: Vozes; 2007.

8 Minayo MCS. O desafio do conhecimento. Pesquisa qualitativa em saúde. 9th ed. São Paulo: Hucitec; 2006.

9. Góes APP, Vieira MRR, Liberatore Júnior RDR. Diabetes mellitus tipo 1 no contexto familiar e social. Rev. paul. pediatr. [Internet]. 2007 [cited 2012 mar 30];25(2):124-8. Available from: http://www.scielo.br/pdf/rpp/v25n2/a05v25n2.pdf.

10. Freitas FV, Sabóia VM. Vivências de adolescentes diabéticos e contribuições da prática educativa da enfermeira. Rev. enferm. UERJ [Internet]. 2007 [cited 2012 mar 30];15(4):569-73. Available from: http://www.facenf.uerj.br/v15n4/v15n4a15.pdf.

11. Nunes MDR, Dupas G, Ferreira NMLA. Diabetes na infância/adolescência: conhecendo a dinâmica familiar. Rev. Eletr. Enf. [Internet] 2007 [cited 2012 mar 30];9(1):119-30. Available from: http://www.fen.ufg.br/revista/v9/n1/v9n1a09.htm.

12. Santos ECB, Zanetti ML, Otero LM, Santos MA. O cuidado sob a ótica do paciente diabético e de seu principal cuidador. Rev Lat Am Enfermagem [Internet]. 2005 [cited 2012 mar 30];13(3):397-406. Available from: http://www.scielo.br/pdf/rlae/v13n3/v13n3a15.pdf. 13. Olevate IC. Estudo atual da doença arterial coronariana em pacientes diabéticos: do tratamento clínico ao procedimento invasivo.Um estudo de revisão. Revista Digital - Buenos Aires. [Internet]. 2010 [cited 2012 mar 30];15(145). Available from: http://www.efdeportes.com/efd145/doenca-arterial-coronarianaem-pacientes-diabeticos.htm.

Artigo recebido em 20.04.2010.

Aprovado para publicação em 13.03.2012.

Artigo publicado em 30.03.2012. 